\title{
Local gene delivery via endovascular stents coated with dodecylated chitosan-plasmid DNA nanoparticles
}

This article was published in the following Dove Press journal:

International Journal of Nanomedicine

2 December 2010

Number of times this article has been viewed

\section{Dunwan Zhu'* \\ $X u$ Jin $^{2 *}$ \\ Xigang Leng' \\ Hai Wang' \\ Junbo Bao' \\ Wenguang $\mathrm{Liu}^{3}$ \\ Kangde $\mathrm{YaO}^{3}$ \\ Cunxian Song'}

'Tianjin Key Laboratory of Biomedical Materials, Institute of Biomedical Engineering, Chinese Academy of Medical Sciences and Peking Union Medical College, Tianjin, China; ${ }^{2}$ Department of Anesthesia and Pain Therapy, Capital Medical University Affiliated Beijing Tiantan Hospital, Beijing, China; ${ }^{3}$ Research Institute of Polymeric Materials, Tianjin University, Tianjin, China; *Both investigators contributed equally to this work and are senior authors.
Correspondence: Xigang Leng Institute of Biomedical Engineering, CAMS and PUMC, Tianjin 300192, China Tel +86228789 I I 9 I

Email lengxgyky@163.com

Cunxian Song

Institute of Biomedical Engineering, CAMS and PUMC, Tianjin 300192, China

Tel +862287892052

Email scxian@tom.com
Abstract: Development of efficacious therapeutic strategies to prevent and inhibit the occurrences of restenosis after percutaneous transluminal coronary angioplasty is critical for the treatment of cardiovascular diseases. In this study, the feasibility and efficiency of stents coated with dodecylated chitosan-plasmid DNA nanoparticles (DCDNPs) were evaluated as scaffolds for localized and prolonged delivery of reporter genes into the diseased blood vessel wall. Dodecylated chitosan-plasmid DNA complexes formed stable positive charged nanospheres with mean diameter of approximately $90-180 \mathrm{~nm}$ and zeta potential of $+28 \pm 3 \mathrm{mV}$. As prepared DCDNPs were spray-coated on stents, a thin layer of dense DCDNPs was successfully distributed onto the metal struts of the endovascular stents as demonstrated by scanning electron microscopy. The DCDNP stents were characterized for the release kinetics of plasmid DNA, and further evaluated for gene delivery and expression both in vitro and in vivo. In cell culture, DCDNP stents containing plasmid EGFP-C1 exhibited high level of GFP expression in cells grown on the stent surface and along the adjacent area. In animal studies, reporter gene activity was observed in the region of the artery in contact with the DCDNP stents, but not in adjacent arterial segments or distal organs. The DCDNP stent provides a very promising strategy for cardiovascular gene therapy.

Keywords: gene delivery, endovascular stent, chitosan, gene nanoparticles

\section{Introduction}

Percutaneous transluminal coronary angioplasty (PTCA) and stent implantation are the major treatment options for coronary heart diseases. However, the incidence of restenosis after PTCA is high, ${ }^{1,2}$ while in-stent restenosis occurred approximately in $10 \%-20 \%$ of patients after the stent implantation. ${ }^{3,4}$ Among the available strategies in preventing restenosis, drug-eluting stent (DES) is currently the most commonly used in clinical practices. ${ }^{5}$ DES functions as a scaffold to hold the dilated segment of artery open. In addition, the surface of bare-metal stents (BMS) is loaded with drugs, such as sirolimus and paclitaxel, which can be released to prevent restenosis by suppressing vascular smooth muscle cell proliferation and modulating the inflammatory and immune responses at the targeted sites. However, there are also intrinsic shortcomings of DES that need to be addressed, such as lack of specific targets in drug effects and the cytotoxicity of the drugs on DES. In addition, DES is also susceptible to an event known as "late stent thrombosis", where blood-clotting inside the stent may occur one or more years post-stent implantation. ${ }^{6}$ Therefore, novel strategies to prevent and treat restenosis are urgently needed and are of great clinical significance. 
Gene therapy is an appealing way to prevent restenosis by delivering therapeutic gene into the vascular tissue. Many previous studies utilized either intravenous (IV) injection or balloon catheter to introduce genes and carriers to blood vessel. Unlike other gene therapies, cardiovascular gene therapy encounters the obstacle of specifically delivering therapeutic gene to the target site, not the blood circulatory system. The use of endovascular stents as scaffolds for localized and prolonged delivery of therapeutic genes into the diseased blood vessel wall would provide a promising solution for gene therapy of in-stent restenosis..$^{7-9}$ However, endovascular stent as a percutaneous gene delivery device needs to improve mainly due to insufficient gene loading.

Chitosan (CS) and its derivatives as nonviral gene transfer carriers have been extensively studied due to their excellent biocompatibility, low immunogenicity, easy preparation, large packaging capacity, and high safety. ${ }^{10}$ They can form polyelectrolyte complexes with negatively charged DNA via electrostatic interaction, thereby effectively protect DNA from nuclease degradation and maintain DNA stability under heat conditions. In vitro gene transfection efficiency of dodecylated chitosan-plasmid DNA nanoparticles (DCDNPs) was evaluated in our previous study, which showed that alkylated chitosan (ACS) resulted in a sevenfold increase in gene transfection in comparison to that of naked plasmid, whereas CS increased the transfection efficiency fourfold. ${ }^{11}$ However, there is no report on the effect of stents coated with dodecylated chitosan (DCS) gene carrier for the prevention and treatment of restenosis.

Herein we report a novel gene delivery approach by successfully tethered gene-loaded DCDNPs on coronary stent, which demonstrated high efficiency in plasmid DNA delivery and gene expression both in vitro and in vivo. Our findings may provide the urgently needed information in facilitating the development of novel, safe, and efficient vascular stents as gene delivery strategy for the prevention and treatment of restenosis.

\section{Materials and methods Instruments and materials}

Zetasizer Nano ZS was obtained from Malvern Instruments Ltd (Malvern, Worcestershire, England). Nikon Eclipse Ti-U inverted research microscope was obtained from Nikon Co (Tokyo, Japan). TD-20/20 luminometer was obtained from Turner BioSystems Inc (Sunnyvale, CA). CAT X120 homogenizer was obtained from CAT Ingenieurbüro M Zipperer GmbH (Staufen, Germany).
Mustang $^{\circledR} 316 \mathrm{~L}$ stainless steel coronary stents $(2.5 \pm 13 \mathrm{~mm})$ were kindly provided by the Microport Medical Co Ltd (Shanghai, China). Dodecylated chitosan $(50 \mathrm{kDa})$ was a generous gift from Dr Wenguang Liu (Tianjin University, China). The characterization of $\mathrm{N}$-alkylated chitosan has been reported previously. ${ }^{12}$ The substitution degree (SD) of alkylated chitosan was determined by potentiometer titration and calculated to be about $20 \%$. Plasmid encoding enhanced green fluorescent protein (pEGFP-C1) was purchased from Clontech (Palo Alto, CA). A pGL3-control vector $(5.3 \mathrm{~kb})$ containing SV40 promoter driven luciferase gene was purchased from Promega (Madison, WI). The plasmids were propagated in Escherichia coli and purified by a Qiagen Endofree Plasmid Mega Kit (Hilden, Germany). Rat arterial smooth muscle cell line (A10) was purchased from American Type Culture Collection (ATCC, Gaithersburg, MD). All other chemicals were of analytical grade. New Zealand White rabbits (male, $3.0-3.5 \mathrm{~kg}$ ) were provided by the Institute of Laboratory Animal Science, Chinese Academy of Medical Sciences and Peking Union Medical College.

\section{Preparation and characterization of the DCDNPs}

The DCDNPs were prepared as reported previously. ${ }^{13}$ Briefly, a $0.02 \%(w / v)$ solution of dodecylated chitosan in $\mathrm{NaAc} / \mathrm{HAc}$ buffer ( $\mathrm{pH} 5.5)$ and a solution of DNA $(1 \mu \mathrm{g} / \mu \mathrm{L})$ in $5 \mathrm{mM}$ sodium chloride solution were prewarmed at $55^{\circ} \mathrm{C}$ for $10 \mathrm{~min}$. The DCDNPs were prepared by mixing the two solutions and vortexing for $40 \mathrm{~s}$ using a CAT X120 homogenizer at various charge ratios (amino group to phosphate group ratio, N/P). Nanoparticles were batch prepared, sterilized by filtering through a $0.22 \mu \mathrm{m}$ filter with low protein binding, and stored at $4^{\circ} \mathrm{C}$ before use. Particle size, distribution, and zeta potential of the nanoparticles were measured on the Zetasizer. The final concentration of plasmid DNA in the DCDNPs suspension was adjusted to $0.1 \mu \mathrm{g} / \mu \mathrm{L}$. Agarose gel electrophoretic retardation assay was employed to investigate the interaction between the polymers and DNA.

\section{Preparation of DCDNPs-loaded stent (NP-stent)}

The DCDNPs-loaded stents were prepared under sterile conditions as follows. Mustang ${ }^{\circledR} 316 \mathrm{~L}$ stainless steel stent was spray-coated with $10 \mu \mathrm{L}$ of the DCDNPs solution, and then dried at $37^{\circ} \mathrm{C}$ for $10 \mathrm{~min}$. The procedure was repeated until a total of $1 \mathrm{~mL}$ DCDNPs suspension was loaded on the surface 
of a single stent. The dried DCDNPs-treated stents were kept sterile at $4^{\circ} \mathrm{C}$ for later evaluation. The amount of DNA loaded on the surface of stent was determined gravimetrically by measuring the weight of BMS and DCDNPs-loaded stent. The morphologies of bare steel stent and NP-stent were analyzed by scanning electron microscopy (SEM).

\section{DNA release kinetics from DCDNPs-loaded stent (NP-stent)}

The release profile of plasmid DNA from DCDNPs-loaded stents was performed as follows. A NP-stent was placed in an Eppendorf tube containing phosphate-buffered saline (PBS; pH 7.4, $137 \mathrm{mM} \mathrm{NaCl}$ ) and was incubated at $37^{\circ} \mathrm{C}$ with centrifuge $(150 \mathrm{rpm})$. In triplicate, $150 \mu \mathrm{L}$ aliquot was transferred into a UV-transparent 96-well plate and the absorbances at $260 \mathrm{~nm}$ were measured by multiplate reader at predetermined intervals. After each measurement, the media was removed and replaced with fresh PBS buffer. The stents were placed back into the tube and returned to the incubator.

\section{In vitro gene transfection mediated by the NP-stent}

NP-stents loaded with pEGFP-C1 plasmid $(n=6)$ were incubated with A10 cell suspension $\left(1 \times 10^{6}\right.$ cells in Dulbecco's modified Eagle's medium [DMEM]) at $37^{\circ} \mathrm{C}$ for $1 \mathrm{~h}$, and then transferred into a $35 \mathrm{~mm}$ culture dish that was preseeded with $1 \times 10^{5} \mathrm{~A} 10$ cells. The cells were incubated in serum-free media for $5 \mathrm{~h}$ followed by the addition of fetal bovine serum (FBS) to a final concentration of $10 \%$. After 48 h, cells were observed under a Nikon Eclipse Ti-U inverted research microscope and fluorescent photographs were taken with a Nikon color-cooled digital camera system. The same experiments were also performed for dodecylated chitosan-coated stents $(n=3)$ and bare steel stents $(n=3)$ as controls.

\section{In vivo gene transfection mediated by the NP-stent}

Animal experiment protocols were reviewed and approved by the Administrative Committee of Animal Experiments, Institute of Biomedical Engineering, Chinese Academy of Medical Sciences and Peking Union Medical College. All procedures involving the use and care of animals conformed to the Guide for the Care and Use of Laboratory Animals published by the US National Institutes of Health.
Two reporter plasmids, pEGFP-C1 and pGL3-control, were used to prepare nanoparticles with dodecylated chitosan and were evaluated for the feasibility of local gene delivery from nanoparticle-coated stents to the target blood vessel wall. All animals received aspirin at $40 \mathrm{mg} / \mathrm{d}$ dosage $24 \mathrm{~h}$ before surgery and each day thereafter. Rabbits $(n=8)$ were sedated with intravenous infusion of sodium pentobarbital (30 $\mathrm{mg} / \mathrm{kg}$ ). The right carotid artery was implanted with a plasmid-loaded NP stent. Similarly, dodecylated chitosancoated stents (containing no plasmid DNA) were implanted into the right carotid artery of rabbits $(n=6)$ as control. Surgical procedure, postoperative medication, and treatments were performed according to the literature. ${ }^{14} \mathrm{All}$ of the animals were sacrificed by an overdose of sodium pentobarbital 7 days after the implantation. The arterial samples were retrieved and evaluated according to methods published previously. ${ }^{15}$ The stented coronary artery segments were then divided into three segments (proximal, medial, and distal). They were embedded in Tissue-Tek OCT compound and slides were cut at $5 \mu \mathrm{m}$ thickness for fluorescence and light microscopy examination. Frozen sections were also prepared and fixed with $4 \%$ paraformaldehyde, counterstained with DAPI, and examined under fluorescent microscopy. GFP immunohistochemistry experiment was performed as previously described. ${ }^{14}$ Hematoxylin and eosin-stained sections were examined under light microscopy. Samples of the lung, liver, kidney, and distal vessel were harvested and examined for gene expression and biodistribution by luciferase assay according to manufacturer's instruction with a Turner TD-20/20 ${ }^{\mathrm{n}}$ luminometer. Relative light units (RLU) were normalized to protein concentration in the cell extracts measured by the BCA method.

\section{Statistical analysis}

The results were presented as mean \pm standard deviation. Data were analyzed using Statistical Packages for Social Sciences program (version 11.0 for Windows; SPSS Inc., Chicago, IL). The significance of differences between means of experimental groups was determined with Student's $t$-test. A $P$-value less than 0.05 was considered significant.

\section{Results and discussion Preparation and characterization of DCDNPs-loaded stents}

Dodecylated chitosan-plasmid DNA complexes at various $\mathrm{N} / \mathrm{P}$ ratios were prepared by complex coacervation, which yielded stable and positively charged nanoparticles with mean diameter of 90-180 nm (Figure 1A) and zeta potential 

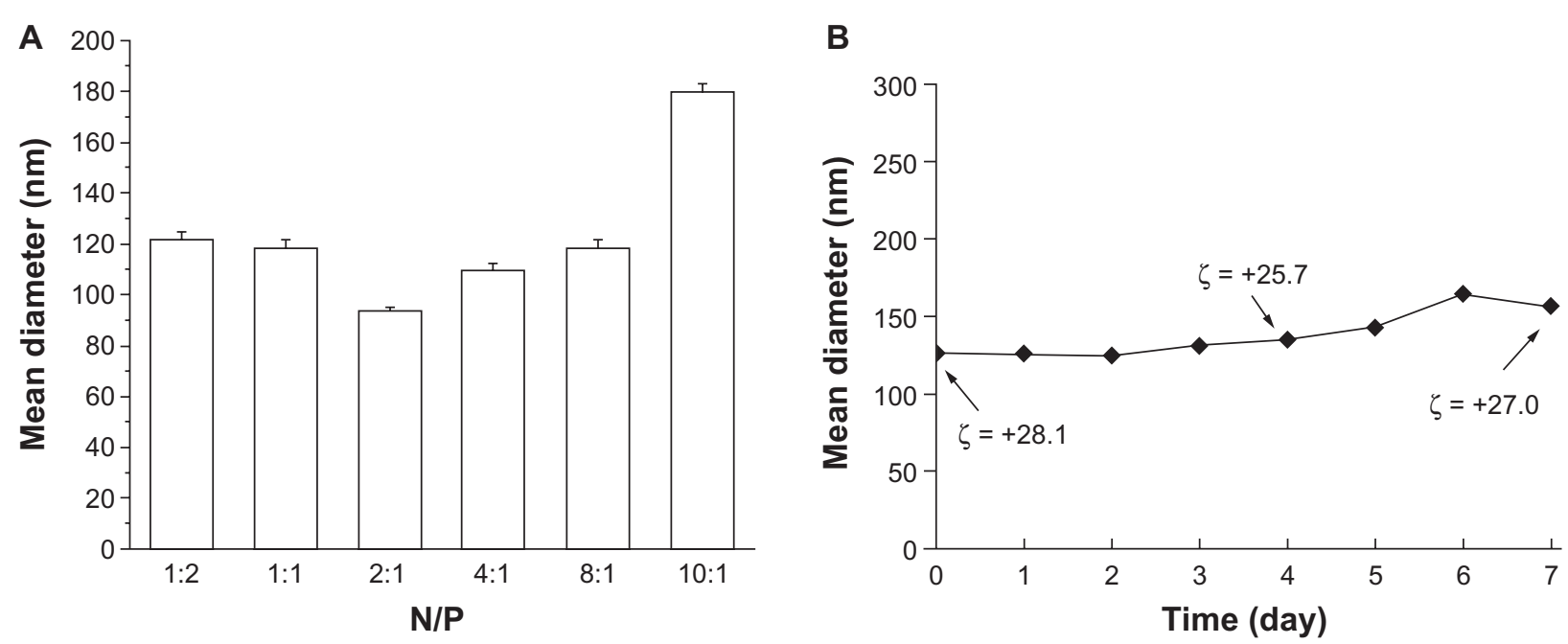

Figure I Mean diameter of dodecylated chitosan-plasmid DNA nanoparticles at different charge ratios (A); Size and zeta potential of dodecylated chitosan-plasmid DNA nanoparticles (at charge ratio of 2:I) over a 7-day incubation period (B).

of $+28 \pm 3 \mathrm{mV}$. Under physiologic condition, the DCDNPs did not show significant change in size and zeta potential over 1-week incubation (Figure 1B).

As demonstrated in Figure 2, a complete retardation of DNA by DCS occurred at charge ratio of 2:1 for CS/DNA complex, whereas the dodecylated chitosan fully entrapped the DNA at the N/P ratio of 1:1. It suggested that not only electrostatic interaction but also hydrophobic interaction contributes to the complex formation between DNA and chitosan derivatives. The incorporation of hydrophobic moieties might cause a cooperative binding transition of alkylated chitosan.

Previous studies using fluorescent particles showed that a size dependency of the transgenic efficacy of nanoparticles, ${ }^{16}$ which indicated that the smallest-sized particles $(\sim 110 \mathrm{~nm}$ in diameter) had the greatest fluorescence intensity within the cell in comparison to the larger-sized particles. Other studies showed an increase in inflammatory responses with particles of 5 10 $\mu \mathrm{m}$ in diameter and no therapeutic response, probably due to uptake by the macrophages and other immune cells rather than smooth muscle cells or endothelial cells. ${ }^{17,18}$ Hence, the current research focused on the dodecylated chitosan/DNA nanoparticles at the charge ratio of $2: 1$, which is of the smallest size in the nanoparticles prepared in the current study.
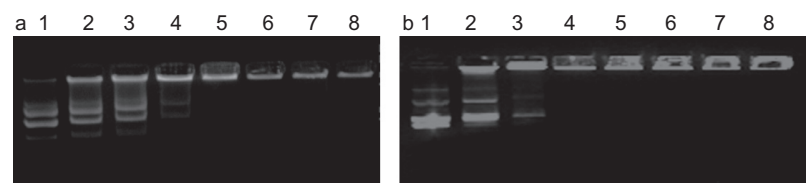

Figure 2 Agarose gel electrophoresis for analysis of CS/DNA (a) or DCS/DNA (b) complexes. Lane I: plasmid DNA, Lane 2: N/P = I:4, Lane 3: N/P = I:2, Lane 4: N/P = I:I, Lane 5: N/P = 2:I, Lane 6: N/P = 4:I, Lane 7: N/P = 8:I, Lane 8: $N / P=10: 1$.
The stents were spray-coated with DCDNPs solution and observed by SEM, with bare steel stent as control. Compared with the control stent (Figure 3A and 3B), DCDNPs were successfully localized on the surface of endovascular stent and a thin layer of dense DCDNPs was observed on the metal struts of endovascular stents (Figure 3C). SEM analysis revealed that DCDNPs were irregularly coated on the surface of the expanded stents as shown at a higher amplification (Figure 3D). It was observed that the morphology of the stent after the release test (Figure 3E) displayed some differences when compared with that before the test, indicating that some parts of the coated layer were detached from the stent. These changes may be due to the fact that the nanoparticles partially detached from the surface of the stent or the complexes formed between the polymer and DNA via electrostatic interaction got unpacked due to the degradation of the polymeric materials. However, the mechanism of the DNA delivery pathway is still not completely understood. Further investigation needs to be conducted to reveal the mechanism underlying the local gene therapy for in-stent restenosis.

Plasmid DNA release profiles from DCDNPs-loaded stents in PBS buffer at $37^{\circ} \mathrm{C}$ were characterized by measuring the absorbance of the solution after each sampling interval; the buffer solution was removed and replaced with fresh PBS buffer ( $\mathrm{pH} 7.4,137 \mathrm{mM} \mathrm{NaCl}$ ) and continued to shake at $37^{\circ} \mathrm{C}$. Figure 4 is a plot of the accumulated solution absorbance at $260 \mathrm{~nm}$ versus incubation time. The results show that there was an initial burst that occurred during the first several hours of incubation, followed by a slight increase in DNA release with prolonged incubation. After 7 days, DNA release was still detected in the supernatant solution, 

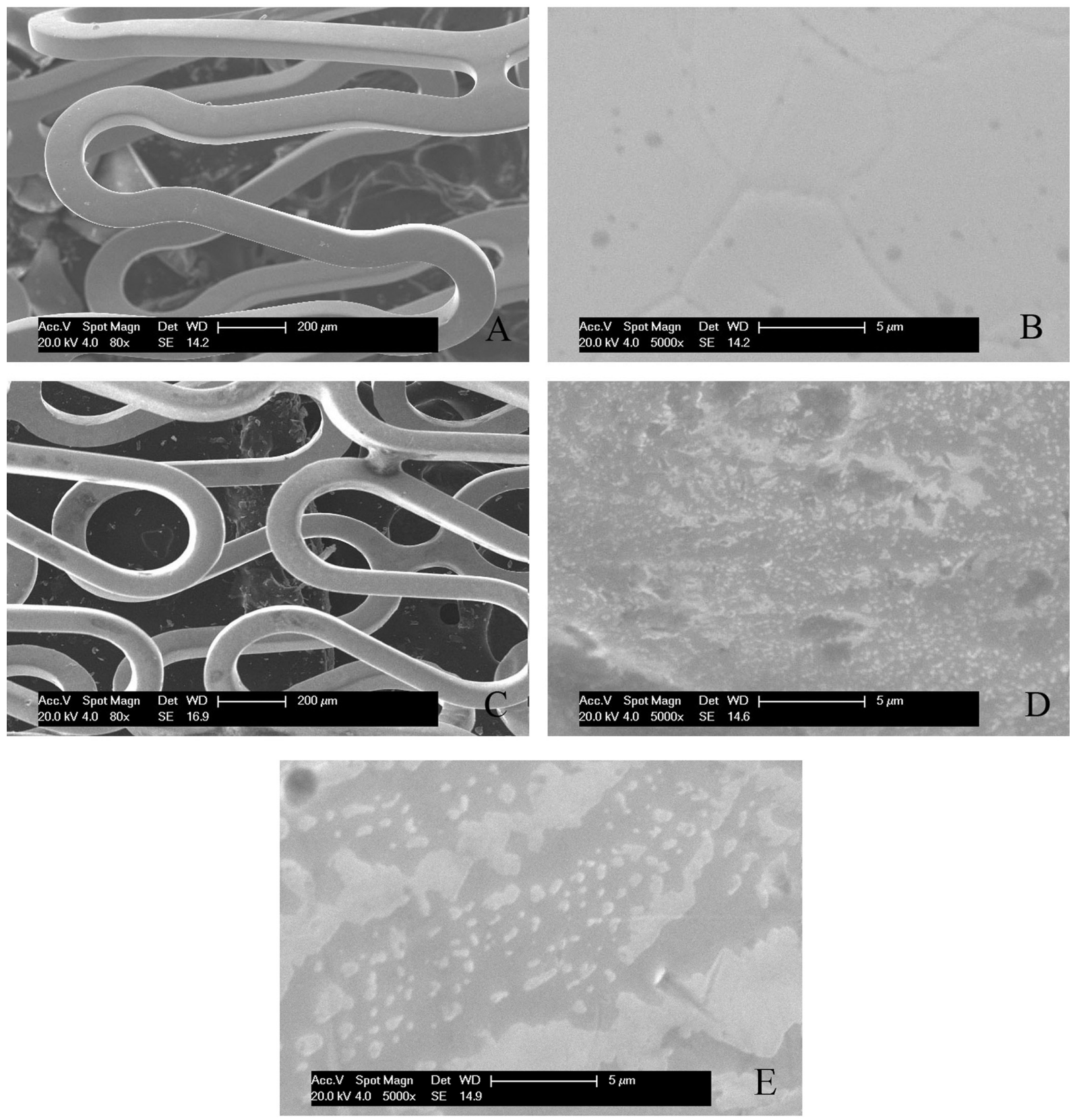

Figure 3 SEM images of DCDNPs-loaded stents. A) bare steel stent; B) bare steel stent at higher amplification; C) NP-stent; D) NP-stent at higher amplification before release test; E) NP-stent at higher amplification after release test.

which strongly suggested that the release of plasmid DNA from the stent surface was sustained over a period of up to 7 days under the experimental conditions.

\section{In vitro gene transfection mediated by DCDNP-loaded stents}

In order to evaluate the capability of DCDNP-loaded stents in delivering genes to target cells, DCDNP-loaded stents were incubated with rat arterial smooth muscle cells (A10 cells). To our surprise, the NP-stents with plasmid
pEGFP-C1 in A10 cell culture induced high level of GFP expression, particularly in the cells grown on the stent surface and along the adjacent area (Figure 5A). In contrast, chitosancoated or bare steel stents (without plasmid DNA) showed no GFP expression (Figure 5B). Moreover, the NP-stents did not show detrimental effects on A10 cell growth.

\section{In vivo gene delivery}

In vivo gene delivery efficiency by pEGFP-C1 loaded NP-stents was examined by implanting the NP-stents 


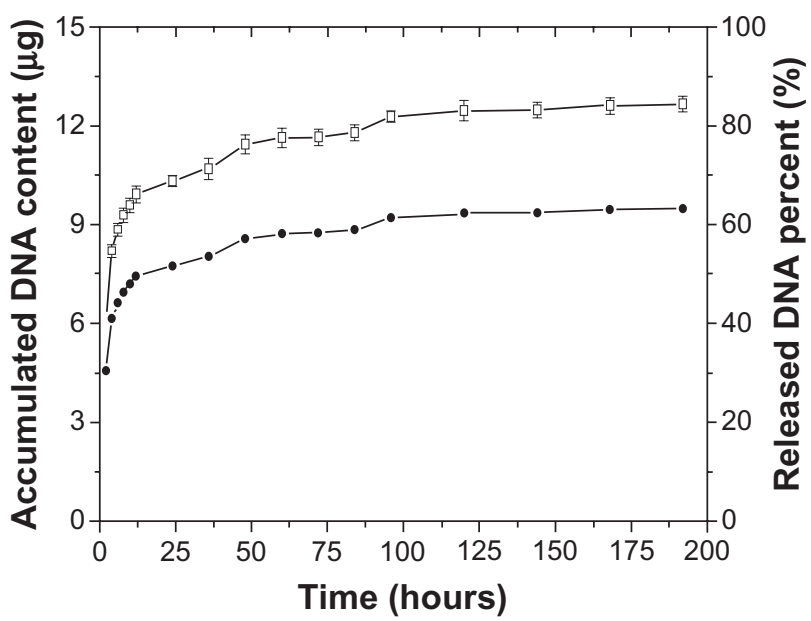

Figure 4 Plasmid DNA release profile from DCDNPs-loaded stents.

surgically into the rabbit right carotid artery; dodecylated chitosan-coated stents (containing no plasmid DNA) were implanted as controls. After removing the tissue section from rabbit common carotid artery (CCA) at the end of the experiment, the samples were embedded in Tissue-Tek OCT compound, followed by fluorescence microscopy analysis of the cut slides. The fluorescent GFP expression in CCA sections was examined and the total number of cells in the same region was determined by DAPI staining. It was found that approximately $12.3 \%$ neointimal cells of CCA were GFP positive, which could be attributed to gene delivery and expression due to the pEGFP-C1 loaded NP-stent (Figure 6).

Furthermore, GFP positive cells were only detected in the neointimal layer that was in close contact with the NP-stent (Figure 7A). The results from immunohistochemical staining using an anti-GFP antibody were also consistent with the fluorescent microscopy analysis. In addition, we observed no distinct inflammatory response from the samples of stentimplanted sites (Figure 7B).

As shown from Figure 8, significantly higher level of luciferase expression was observed on the arterial samples that had been in close contact with NP-stent loaded with
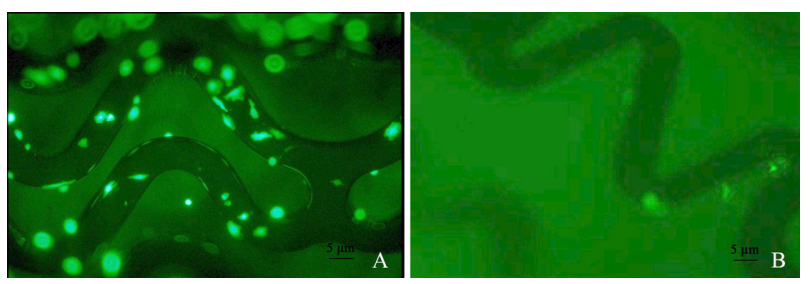

Figure 5 GFP expressions in AI 0 cells incubated with pEGFP-CI loaded NP-stents. A) pEGFP-Cl-loaded NP-stents; B) dodecylated chitosan-coating stent (no plasmid DNA) (FITC, I00X).

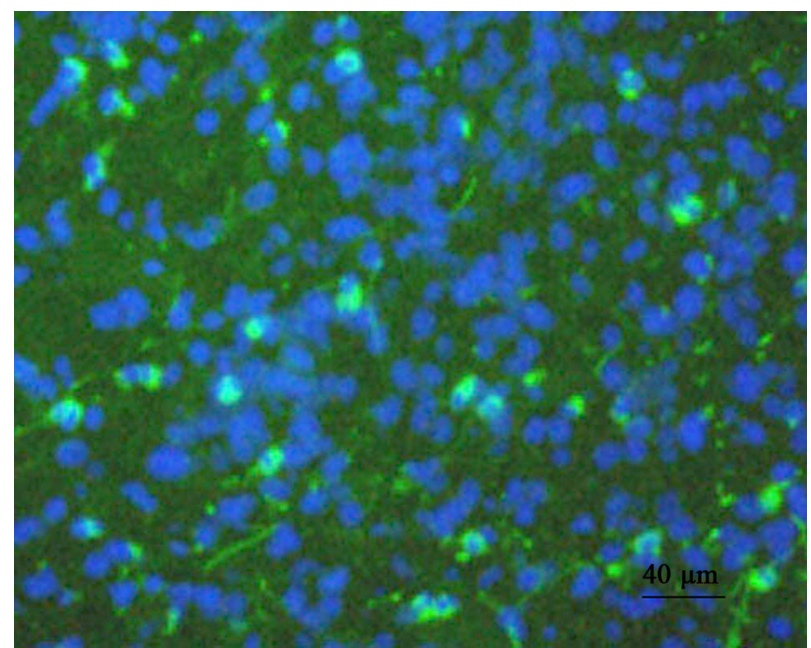

Figure 6 Rabbit CCA results demonstrating cells expressing GFP mediated by pEGFP-Cl-loaded NP stents in vivo.

pGL3-control plasmid in comparison to that of the control group. However, luciferase expression was comparable to background from the samples of artery $1.5-\mathrm{cm}$ away from stented site, contralateral carotid artery, and abdominal artery. Trace luciferase expressions were detected from two liver specimens, while no luciferase expression was found from other specimens from distal organs that included the heart, lung, brain, and kidney. The artery and tissue samples from the control groups were negative for luciferase expression. Therefore, DNA-loaded stent significantly $(P<0.01)$ improved the gene delivery and expression in the stent implanted site compared with other sites.

Endovascular stents coated with gene nanoparticles may provide a novel means of gene delivery system for endovascular gene therapy. However, currently there is no effective gene-coated stent that can safely and specifically deliver target therapeutic genes to the cardiovascular target cells and not be lost in the blood circulation system. Moreover, it remains technically challenging to evenly and completely coat the stent with target genes. Alkylated chitosan could improve the thermal stability of DNA, protect
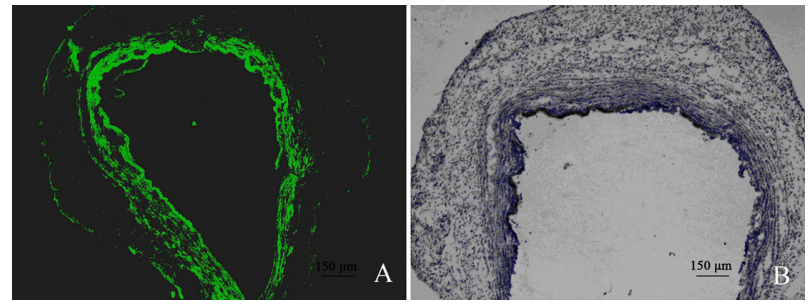

Figure 7 Rabbit CCA results demonstrating GFP transduction in arterial wall: A) Example of GFP expression following NP-stent implanting (FITC; 50X); B) Immunohistochemical confirmation of GFP expression (immunoperocidase; 50×). 


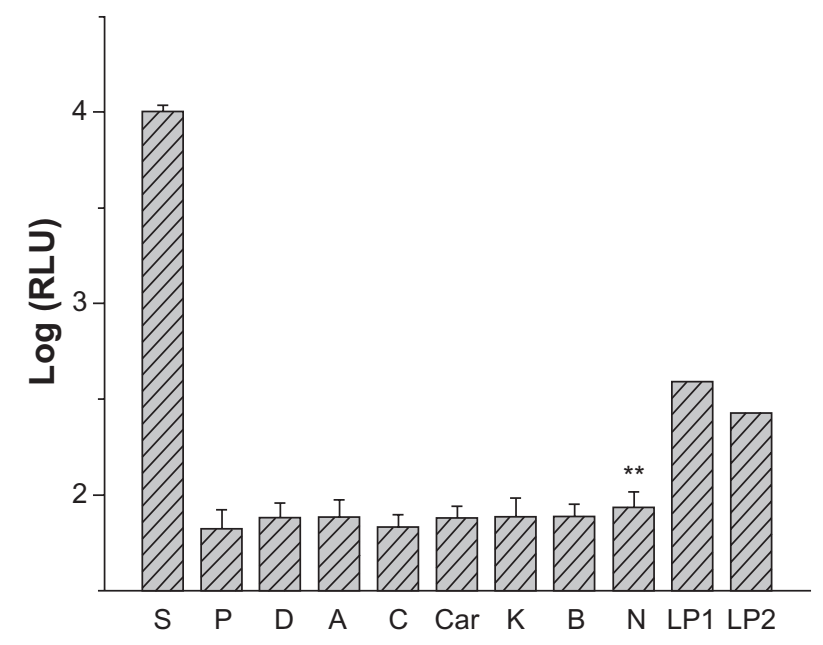

Figure 8 Relative luciferase expression of vessel wall and tissue samples (7 days after DCDNPs-loaded stents implanted).

Abbreviations: S, CCA with implanted stent; $P, C C A$ proximal $3 \mathrm{~cm}$; D, CCA distal $3 \mathrm{~cm}$; A, abdominal aorta; C, contralateral CCA; Car, cardiac muscle; L, liver; $\mathrm{K}$, kidney; B, encephalon; N, control artery; LPI, liver positive I; LP2, liver positive 2.

DNA from enzyme degradation by DNase, and enhance gene transfection efficiency. It is proposed that the higher transfection efficiency of ACS is attributed to the increased entry into cells facilitated by hydrophobic interactions and easier unpacking of DNA from ACS carriers due to the weakening of electrostatic attractions between DNA and ACS. ${ }^{11}$ In this study, we combined the advantages of DCDNPs as a low toxic and high efficient nonviral vector with the inherent feature of coronary stent and accomplished effective intravascular delivery of plasmid DNA.

It was estimated that under in vivo conditions, a small amount of DCDNPs coated on a stent surface could be washed off by blood flow into the blood circulation and absorbed by the reticuloendothelial system, which is mainly distributed in organs such as liver, spleen, and bone marrow. Reticuloendothelial system functions to absorb microparticles and nanoparticles by phagocytosis. Therefore, a low level of luciferase and GFP expression was observed in liver and this result is consistent with previous results showing that intravenous injection of chitosan nanoparticles often leads to liver aggregation. ${ }^{19}$ Since chitosan itself is nontoxic and only a small amount of chitosan reaches the liver, the effect is negligible. Overall, we observed no significant side effects. For future studies, we will explore novel strategies to covalently tether DCDNPs onto metal stent surface in order to further improve the local delivery and expression efficiency. The use of DCDNPs has demonstrated to be an attractive route for improving both the safety and efficiency of therapeutic gene delivery.

\section{Conclusion}

In this study, we investigated the feasibility and efficiency of DCDNPs-coated stent as scaffolds for localized and prolonged delivery of reporter genes into a diseased blood vessel wall. We successfully demonstrated that bare metal stents spraycoated with DCDNPs were able to continuously release target DNAs. This facilitated the delivery of therapeutic genes into the targeted artery wall cells and resulted in remarkable local gene transfection and expression both in vitro and in vivo. The results demonstrate a significant progress in the local delivery of plasmid DNA into intravascular tissue for gene therapy of restenosis. In addition to the high gene transfection efficiency, the DCDNPs-stent system also has the advantages of easy fabrication, biocompatibility, and low immunogenicity. This system could be a very promising cardiovascular gene therapy strategy for diseases such as in-stent restenosis.

\section{Acknowledgment/Disclosure}

This work was supported by the National Natural Science Foundation of China (grant nr 50673100, 50873114, 50830106) and the Ministry of Science and Technology of China (grant nr 2005DIB1J094, 2006CB933203). The authors report no conflicts of interest. The authors are solely responsible for the content and writing of the paper.

\section{References}

1. Williams DO, Holubkov R, Yeh W, et al. Percutaneous coronary intervention in the current era compared with 1985-1986: the National Heart, Lung, and Blood Institute Registries. Circulation. 2000;102(24): 2945-2951.

2. Mehran R, Dangas G, Abizaid AS, et al. Angiographic patterns of in-stent restenosis: classification and implications for long-term outcome. Circulation. 1999;100(18):1872-1878.

3. Fischman DL, Leon MB, Baim DS, et al. A randomized comparison of coronary-stent placement and balloon angioplasty in the treatment of coronary artery disease. Stent Restenosis Study Investigators. N Engl J Med. 1994;331(8):496-501.

4. Serruys PW, Foley DP, Suttorp MJ, et al. A randomized comparison of the value of additional stenting after optimal balloon angioplasty for long coronary lesions: final results of the additional value of NIR stents for treatment of long coronary lesions (ADVANCE) study. J Am Coll Cardiol. 2002;39(3):393-399.

5. Babapulle MN, Eisenberg MJ. Coated stents for the prevention of restenosis: Part I. Circulation. 2002;106(21):2734-2740.

6. Farb A, Boam AB. Stent thrombosis redux-the FDA perspective. N Engl J Med. 2007;356(10):984-987.

7. Levy RJ, Song C, Tallapragada S, et al. Localized adenovirus gene delivery using antiviral IgG complexation. Gene Ther. 2001;8(9): 659-667

8. Sharif F, Daly K, Crowley J, O'Brien T. Current status of catheter- and stent-based gene therapy. Cardiovasc Res. 2004;64(2):208-216.

9. Jin X, Mei L, Song C, et al. Immobilization of plasmid DNA on an anti-DNA antibody modified coronary stent for intravascular site-specific gene therapy. J Gene Med. 2008;10(4):421-429. 
10. Roy K, Mao HQ, Huang SK, Leong KW. Oral gene delivery with chitosan-DNA nanoparticles generates immunologic protection in a murine model of peanut allergy. Nat Med. 1999;5(4):387-391.

11. Liu WG, Zhang X, Sun SJ, et al. N-alkylated chitosan as a potential nonviral vector for gene transfection. Bioconjug Chem. 2003;14(4): 782-789.

12. Li F, Liu WG, Yao KD. Preparation of oxidized glucose-crosslinked $\mathrm{N}$-alkylated chitosan membrane and in vitro studies of $\mathrm{pH}$-sensitive drug delivery behaviour. Biomaterials. 2002;23(2):343-347.

13. Mao HQ, Roy K, Troung-Le VL, et al. Chitosan-DNA nanoparticles as gene carriers: synthesis, characterization and transfection efficiency. J Control Release. 2001;70(3):399-421.

14. Klugherz BD, Jones PL, Cui X, et al. Gene delivery from a DNA controlled-release stent in porcine coronary arteries. Nat Biotechnol. 2000; 18(11):1181-1184.

15. Klugherz BD, Song C, DeFelice S, et al. Gene delivery to pig coronary arteries from stents carrying antibody-tethered adenovirus. Hum Gene Ther. 2002;13(3):443-454.
16. Westedt U, Barbu-Tudoran L, Schaper AK, Kalinowski M, Alfke H, Kissel T. Deposition of nanoparticles in the arterial vessel by porous balloon catheters: localization by confocal laser scanning microscopy and transmission electron microscopy. AAPS Pharm Sci. 2002;4(4):E41.

17. Gradus-Pizlo I, Wilensky RL, March KL, et al. Local delivery of biodegradable microparticles containing colchicine or a colchicine analogue: effects on restenosis and implications for catheter-based drug delivery. J Am Coll Cardiol. 1995;26(6):1549-1557.

18. Dev V, Eigler N, Fishbein MC, et al. Sustained local drug delivery to the arterial wall via biodegradable microspheres. Cathet Cardiovasc Diagn. 1997;41(3):324-332.

19. Leong KW, Mao HQ, Truong-Le VL, Roy K, Walsh SM, August JT. DNA-polycation nanospheres as non-viral gene delivery vehicles. J Control Release. 1998;53(1-3):183-193.

\section{Publish your work in this journal}

The International Journal of Nanomedicine is an international, peerreviewed journal focusing on the application of nanotechnology in diagnostics, therapeutics, and drug delivery systems throughout the biomedical field. This journal is indexed on PubMed Central, MedLine, CAS, SciSearch ${ }^{\circledR}$, Current Contents ${ }^{\circledR} /$ Clinical Medicine,
Journal Citation Reports/Science Edition, EMBase, Scopus and the Elsevier Bibliographic databases. The manuscript management system is completely online and includes a very quick and fair peer-review system, which is all easy to use. Visit http://www.dovepress.com/ testimonials.php to read real quotes from published authors. 